\title{
Cinnamaldehyde and cinnamaldehyde derivatives reduce virulence in Vibrio spp. by decreasing the DNA-binding activity of the quorum sensing response regulator LuxR
}

\author{
Gilles Brackman ${ }^{1}$, Tom Defoirdt ${ }^{2,3}$, Carol Miyamoto ${ }^{4}$, Peter Bossier ${ }^{3}$, \\ Serge Van Calenbergh ${ }^{5}$, Hans Nelis ${ }^{1}$ and Tom Coenye*1
}

Address: ${ }^{1}$ Laboratory of Pharmaceutical Microbiology, Ghent University, Harelbekestraat 72, B-9000 Ghent, Belgium, ${ }^{2}$ Laboratory of Microbial Ecology and Technology, Ghent University, Coupure Links 653, 9000 Ghent, Belgium, ${ }^{3}$ Laboratory of Aquaculture and Artemia Reference Center, Ghent University, Rozier 44, 9000 Ghent, Belgium, ${ }^{4}$ Department of Biochemistry, McGill University, McIntyre Medical Sciences Building, Room 818, 3655 Promenade Sir William Osler, Montreal, H3G 1Y6, Canada and ${ }^{5}$ Laboratory of Medicinal Chemistry, Ghent University, Harelbekestraat 72, B-9000 Ghent, Belgium

Email: Gilles Brackman - gilles.brackman@ugent.be; Tom Defoirdt - tom.defoirdt@ugent.be; Carol Miyamoto - carol.miyamoto@mcgill.ca; Peter Bossier - peter.bossier@ugent.be; Serge Van Calenbergh - serge.vancalenbergh@ugent.be; Hans Nelis - hans.nelis@ugent.be;

Tom Coenye* - Tom.Coenye@UGent.be

* Corresponding author

Published: 16 September 2008

BMC Microbiology 2008, 8:149 doi:10.1186/147|-2180-8-149
Received: 23 April 2008

Accepted: 16 September 2008

This article is available from: http://www.biomedcentral.com/I47I-2I80/8/149

(c) 2008 Brackman et al; licensee BioMed Central Ltd.

This is an Open Access article distributed under the terms of the Creative Commons Attribution License (http://creativecommons.org/licenses/by/2.0), which permits unrestricted use, distribution, and reproduction in any medium, provided the original work is properly cited.

\begin{abstract}
Background: To date, only few compounds targeting the Al-2 based quorum sensing (QS) system are known. In the present study, we screened cinnamaldehyde and substituted cinnamaldehydes for their ability to interfere with Al-2 based QS. The mechanism of QS inhibition was elucidated by measuring the effect on bioluminescence in several Vibrio harveyi mutants. We also studied in vitro the ability of these compounds to interfere with biofilm formation, stress response and virulence of Vibrio spp. The compounds were also evaluated in an in vivo assay measuring the reduction of Vibrio harveyi virulence towards Artemia shrimp.
\end{abstract}

Results: Our results indicate that cinnamaldehyde and several substituted derivatives interfere with Al-2 based QS without inhibiting bacterial growth. The active compounds neither interfered with the bioluminescence system as such, nor with the production of Al-2. Study of the effect in various mutants suggested that the target protein is LuxR. Mobility shift assays revealed a decreased DNA-binding ability of LuxR. The compounds were further shown to (i) inhibit biofilm formation in several Vibrio spp., (ii) result in a reduced ability to survive starvation and antibiotic treatment, (iii) reduce pigment and protease production in Vibrio anguillarum and (iv) protect gnotobiotic Artemia shrimp against virulent Vibrio harveyi BB 120.

Conclusion: Cinnamaldehyde and cinnamaldehyde derivatives interfere with Al-2 based QS in various Vibrio spp. by decreasing the DNA-binding ability of LuxR. The use of these compounds resulted in several marked phenotypic changes, including reduced virulence and increased susceptibility to stress. Since inhibitors of Al-2 based quorum sensing are rare, and considering the role of Al-2 in several processes these compounds may be useful leads towards antipathogenic drugs. 


\section{Background}

Vibriosis, caused by Vibrio spp., is a major disease of marine fish and shellfish and is an important cause of economic loss in aquaculture $[1,2]$. Until recently prophylactic antibiotics were extensively used in aquaculture $[3,4]$. However, overuse of antibiotics resulted in increased rates of resistance so that novel approaches are required to manage vibriosis [5]. A possible novel target is the bacterial communication system. Bacteria monitor their population densities through the production and sensing of small signal molecules called autoinducers, a process entitled as quorum sensing (QS). To date three types of QS systems have been identified in Vibrio spp. [6]. Acylated homoserine lactones (AHL) are used as signal molecules in the LuxM/N QS system [7], while in the CqsA/S system, (S)-3-hydroxytridecan-4-one ("Cholera autoinducer 1", CAI-1) is used [8]. A third QS system appears to be shared by many Gram-positive and Gram-negative bacteria and is based on a mixture of interconvertible molecules collectively referred to as autoinducer-2 (AI-2) [9]. A key enzyme in the production of AI-2 is LuxS. LuxS catalyzes the cleavage of S-ribosylhomocysteine to homocysteine and 4,5-dihydroxy-2,3-pentanedione (DPD) [10]. DPD will subsequently undergo spontaneous derivatizations, forming a mixture of molecules, including $(2 \mathrm{R}, 4 \mathrm{~S})-2$ methyl-2,3,3,4-tetrahydroxytetrahydrofuran (R-THMF) and (2S,4S)-2-methyl-2,3,3,4-tetrahydroxytetrahydrofuran-borate (S-THMF-borate) [11]. Although not all QS systems are present in all Vibrio spp., most of them contain the AI-2 based QS system [12]. In Vibrio spp. AI-2 binds to LuxP, a periplasmic AI-2 receptor that is associated with the LuxQ sensor kinase-phosphatase. At low population density only basal amounts of diffusible signal molecules are produced, and in this situation LuxQ will act as a kinase resulting in a phosphorylation of the response regulator LuxO through a cascade involving LuxU. Phosphorylation activates LuxO resulting in the production of small regulatory RNAs [13]. These small RNAs, together with the chaperone protein $\mathrm{Hfq}$, will destabilize mRNA encoding the response regulator LuxR. However, when population density is sufficiently high, AI-2 will bind to LuxP and as a result LuxQ will act as a phosphatase, leading to a dephosphorylation of LuxO [14]. Since dephosphorylated LuxO is inactive, no small regulatory RNAs will be formed and the LuxR mRNA remains stable, resulting in the production of LuxR and ultimately an altered gene expression pattern. AI-2 based QS was found to play an important role in regulating the production of several virulence factors, biofilm formation and stress responses in several Vibrio spp. [15-17] and it was found to be associated with virulence as shown in several in vivo assays $[18,19]$. In contrast, in Vibrio cholerae, CAI-1 was found to be the principle signal molecule in virulence regulation [8]. Because of this involvement in virulence, inhibitors of AI-2 based QS have been proposed as novel antipathogenic agents. While there is a growing interest in and evidence for the use of these antipathogenic substances to interfere with interspecies QS in the control of virulence and biofilm formation, only a few inhibitors of AI-2 based QS are known, including halogenated furanones and cinnamaldehyde [20-23]. Halogenated furanones have previously been shown to disrupt AHL and AI-2 based quorum sensing in Vibrio spp. by decreasing the DNA-binding activity of the response regulator LuxR [24-26]. Halogenated furanones can attenuate the virulence of several Vibrio spp. in gnotobiotic brine shrimp Artemia franciscana and their use results in a reversal of the negative effects of Vibrio harveyi BB120 towards rotifers $[27,28]$. Unfortunately, the toxicity of halogenated furanones towards both brine shrimp and rotifers limits their use. In contrast, cinnamaldehyde is a non-toxic synthetic flavouring substance that is widely used in food, beverages, chewing gum, and the perfume and food chemistry, and is generally recognised as safe [29]. Cinnamaldehyde concentrations in food range from 4 ppm to more than 300 ppm [30]. Although cinnamaldehyde is known to be a QS-inhibitor [21], its exact mechanism of action remains to be elucidated. The goal of the present study was to determine the mechanism of action of cinnamaldehyde and to evaluate its effect on virulence of Vibrio spp. in vitro and in vivo.

\section{Results and discussion \\ Effect of cinnamaldehyde and cinnamaldehyde derivatives on microbial growth}

When used in concentrations up to $150 \mu \mathrm{M}$, cinnamaldehyde and most cinnamaldehyde derivatives (Fig. 1) had no inhibitory effect on the growth of strains in the present study (data not shown). The same was true for $4-\mathrm{NO}_{2}$-cinnamaldehyde, but only in concentrations up to $50 \mu \mathrm{M}$. In all further experiments, $100 \mu \mathrm{M}$ was used (except for 4 $\mathrm{NO}_{2}$-cinnamaldehyde, $25 \mu \mathrm{M}$ ), unless otherwise mentioned.

\section{Effect of cinnamaldehyde and 2-NO $\mathrm{N}_{2}$-cinnamaldehyde on bioluminescence}

To rule out direct interference with the bioluminescence system of Vibrio harveyi, a constitutively bioluminescent strain was constructed. A plasmid containing luxCDABE genes under lacZ promotion was conjugated into Escherichia coli DH5 $\alpha$ (a strain defective in AI-2 production). The bioluminescence was not inhibited by cinnamaldehyde and cinnamaldehyde derivatives (data not shown) and these results indicate that the enzymes of Vibrio harveyi involved in bioluminescence are not inhibited by cinnamaldehyde or cinnamaldehyde derivatives. 
<smiles>[R]c1ccc(/C=C/C=O)c([R2])c1</smiles>

\begin{tabular}{ccccc}
\hline Compound & abbreviation & $\mathrm{R} 1$ & $\mathrm{R} 2$ & $\begin{array}{c}\mathrm{MW} \\
(\mathrm{g} / \mathrm{mol})\end{array}$ \\
\hline Cinnamaldehyde & $\mathrm{CA}$ & $\mathrm{H}$ & $\mathrm{H}$ & 132.16 \\
4-methoxy-cinnamaldehyde & 4-MeO-CA & $\mathrm{OMe}-$ & $\mathrm{H}$ & 162.19 \\
2-methoxy-cinnamaldehyde & 2-MeO-CA & $\mathrm{H}$ & $\mathrm{OMe}-$ & 162.19 \\
4-nitro-cinnamaldehyde & 4- $\mathrm{NO}_{2}-\mathrm{CA}$ & $\mathrm{NO}_{2-}$ & $\mathrm{H}$ & 177.16 \\
2-nitro-cinnamaldehyde & 2- $\mathrm{NO}_{2}-\mathrm{CA}$ & $\mathrm{H}$ & $\mathrm{NO}_{2-}$ & 177.16 \\
4-dimethyl-amino- & 4- $\mathrm{Me}_{2} \mathrm{~N}-\mathrm{CA}$ & $\mathrm{Me}_{2} \mathrm{~N}-$ & $\mathrm{H}$ & 175.23 \\
cinnamaldehyde & & & & \\
\hline
\end{tabular}

\section{Figure I}

Cinnamaldehyde and cinnamaldehyde derivatives used in this study.

Effect of cinnamaldehyde and cinnamaldehyde derivatives on Al-2 based QS

Since bioluminescence is a QS regulated phenotype in Vibrio harveyi, we evaluated the effect of the different compounds on bioluminescence in this species. In a first screening we used Vibrio harveyi BB170. It was observed that all of the compounds blocked the AI-2 QS system in a concentration-dependent way (Fig. 2). At $100 \mu \mathrm{M}$, cinnamaldehyde and 2- $\mathrm{NO}_{2}$-cinnamaldehyde were found to be the most active compounds, yielding an inhibition of $65 \pm 13 \%$ and $62 \pm 7 \%$, respectively. $2-\mathrm{MeO}$-cinnamaldehyde, 4-MeO-cinnamaldehyde and $4-\mathrm{Me}_{2} \mathrm{~N}$-cinnamalde-

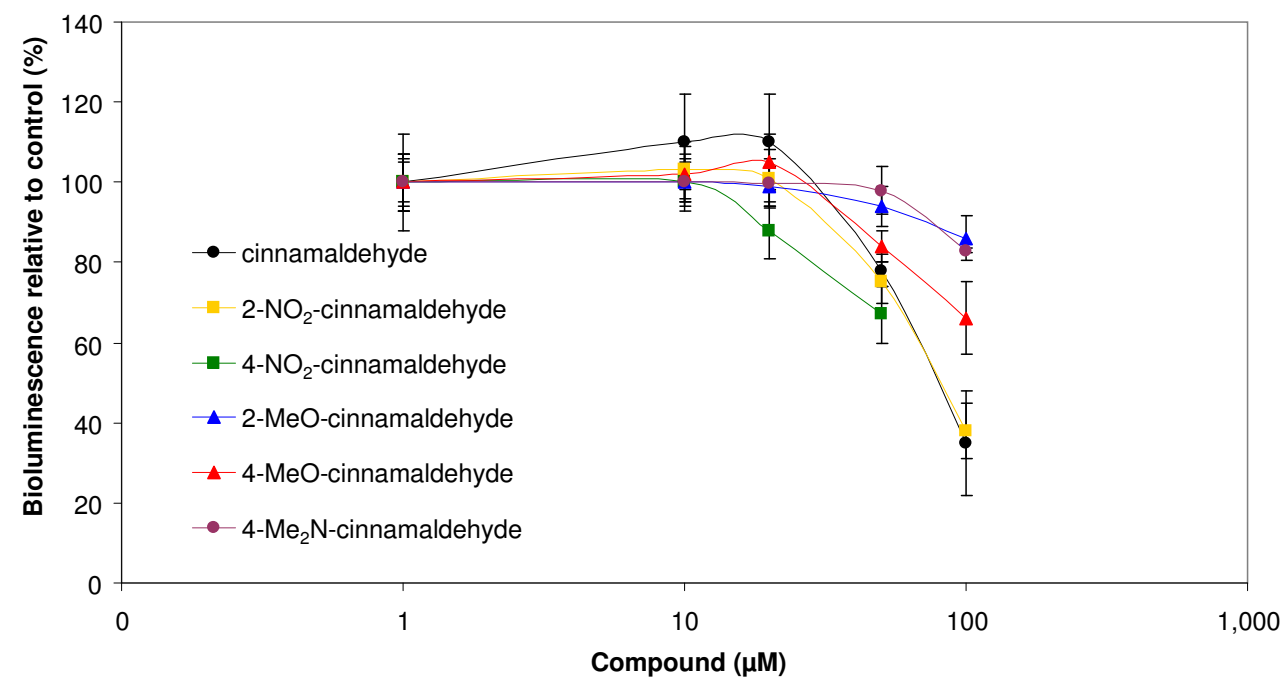

\section{Figure 2}

Effect of cinnamaldehyde and cinnamaldehyde derivatives on Al-2 based QS. Bioluminescence in Vibrio harveyi $\mathrm{BB} I 70$ as a function of the concentration of cinnamaldehyde and cinnamaldehyde derivatives. Bioluminescence measurements were performed $6 \mathrm{~h}$ after the addition of the compounds. Bioluminescence of the control (without addition of compound) was set at $100 \%$ and the responses for other samples were normalised accordingly. The error bars represent the standard deviation. 
hyde were found to be less active at this concentration, with inhibitions of $14 \pm 5 \%, 34 \pm 9 \%$ and $17 \pm 1 \%$, respectively. The effect of 4- $\mathrm{NO}_{2}$-cinnamaldehyde was only evaluated at lower concentrations because of its growth inhibitory effect. It was found to be the most active compound at concentrations of 25 and $50 \mu \mathrm{M}$, with inhibitions of $12 \pm 11 \%$ and $33 \pm 7 \%$, respectively. In general, the QS inhibition assay detected several active QS inhibitors and some striking structure-activity relationships. The inhibitory effect was highly dependent on the substitution pattern of the aromatic ring. Replacement of the dimethylamine $\left(\mathrm{Me}_{2} \mathrm{~N}\right)$ substituent with a methoxy $(\mathrm{MeO})$ or a nitro $\left(\mathrm{NO}_{2}\right)$ group enhanced the activity. In both the methoxy and the nitro series the activity dropped (approximately $\pm 10-20 \%$ ) upon moving the substituent from the para to the ortho position. In general, no cinnamaldehyde derivative was found to be more active than the unsubstituted cinnamaldehyde at concentrations of $100 \mu \mathrm{M}$ and only one compound, 2- $\mathrm{NO}_{2}$-cinnamaldehyde, was found to result in the same level of inhibition. At lower concentrations, 4- $\mathrm{NO}_{2}$-cinnamaldehyde was significantly more active than the unsubstituted cinnamaldehyde, but the growth inhibitory effect of this compound prohibited its testing at higher concentrations.

\section{Effect of cinnamaldehyde and cinnamaldehyde derivatives on the bioluminescence of Vibrio harveyi QS mutants}

Bioluminescence in Vibrio harveyi BB170 is mainly controlled by $\mathrm{AI}-2$, as this strain is not responsive to AHL stimulation [7]. Hence we limited the possible target of cinnamaldehyde and cinnamaldehyde derivatives to the AI-2 QS system. To determine the molecular target within the AI-2 QS pathway we measured the effect of cinnamaldehyde and cinnamaldehyde derivatives on the bioluminescence in different QS mutants. Vibrio harveyi MM30 has a mutation in the luxS gene, making it incapable of producing AI-2. However, this strain will react to exogenously added AI-2 with activation of the QS transduction system leading to bioluminescence. Inhibition of bioluminescence in this mutant would suggest the absence of an inhibitory effect on LuxS. Further we evaluated the effect of the test compounds on the production of AI-2 in Escherichia coli K12. The Vibrio harveyi JAF553 and JAF483 mutants contain a point mutation in the luxU and luxO genes, respectively, thereby preventing their phosphorelay capacity. Vibrio harveyi BNL258 has a Tn5 insertion in the $h f q$ gene, resulting in a non-functional Hfq protein. Vibrio harveyi strains JAF553, JAF483 and BNL258 are all constitutively luminescent and inhibition of bioluminescence in one of these indicates that the cinnamaldehyde compounds act downstream of the mutated protein. Cinnamaldehyde and 2- $\mathrm{NO}_{2}$-cinnamaldehyde were found to block bioluminescence in Vibrio harveyi MM30 (Fig. 3),

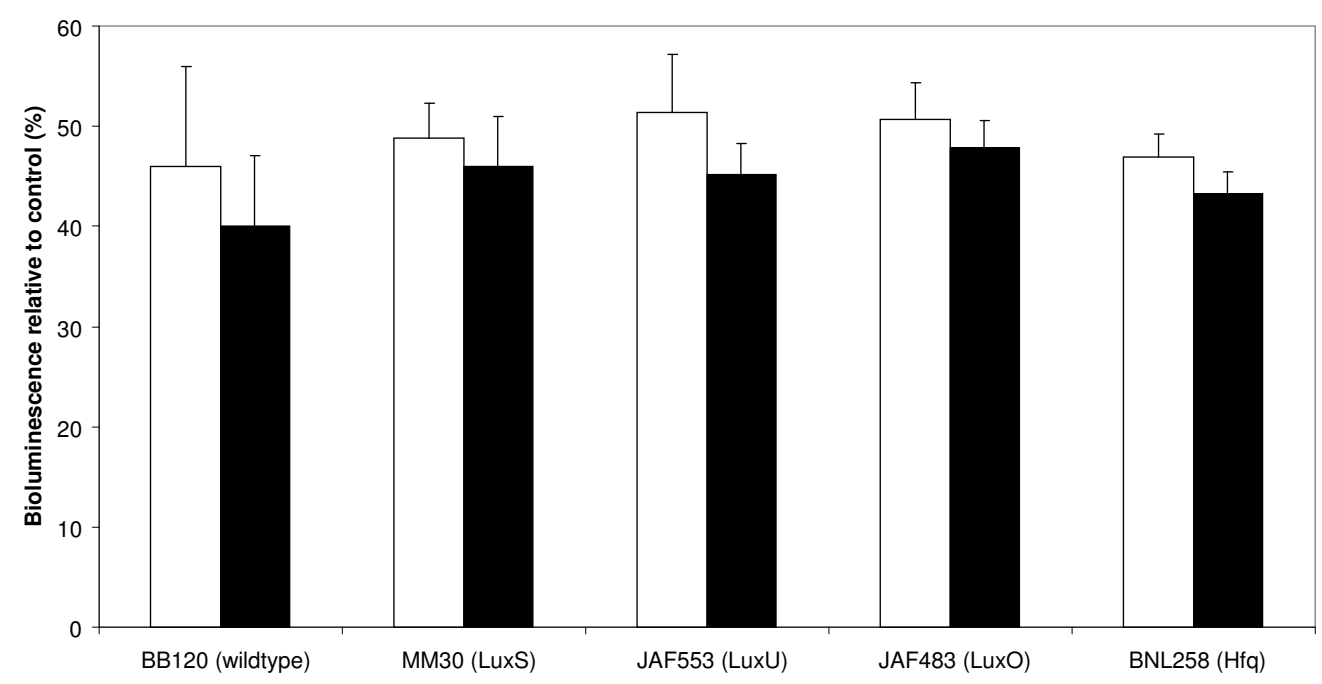

Figure 3

Effect of cinnamaldehyde and 2- $\mathrm{NO}_{2}$-cinnamaldehyde on the bioluminescence of wild type Vibrio harveyi BB I 20 and the different Vibrio harveyi QS mutants. The percentage of bioluminescence of the Vibrio harveyi wild type BBI 20 and the mutants MM30, JAF553, JAF483 and BNL258 with $100 \mu \mathrm{M}$ cinnamaldehyde (white bars) or $100 \mu \mathrm{M} 2-\mathrm{NO}_{2}-\mathrm{cinnamaldehyde}$ (black bars) are presented. Measurements were performed $6 \mathrm{~h}$ after the addition of the compounds. Bioluminescence of the control (without addition of compound) was set at 100\% and the response for the other samples were normalised accordingly. The error bars represent the standard deviation. 
suggesting that these compounds do not exert their effect at the level of AI-2 production but rather at the level of the QS transduction system. Affirmatively, the supernatants of Escherichia coli K12 treated with cinnamaldehyde and cinnamaldehyde derivatives revealed no difference in AI2 activity compared to the control (data not shown). Cinnamaldehyde and $2-\mathrm{NO}_{2}$-cinnamaldehyde were found to block bioluminescence to the same extent in all other mutants tested (Fig. 3). This suggests that the target of cinnamaldehyde and cinnamaldehyde derivatives is the downstream component of the AI-2 signalling transduction pathway, the transcriptional regulatory protein LuxR.

\section{Effect of cinnamaldehyde on LuxR protein levels and on LuxR DNA-binding activity}

Using purified LuxR protein, the presence of $0.19 \mathrm{mM}$ and $0.75 \mathrm{mM}$ cinnamaldehyde resulted in a maximal difference in LuxR DNA shift compared to the untreated control (Fig. 4a). These data indicate that in vitro binding of the transcriptional regulator LuxR to its promoter sequence is affected in the presence of cinnamaldehyde. Surprisingly, when adding higher concentrations of cinnamaldehyde (1.9 mM) no difference in shift could be observed anymore. This inconsistency was also observed for high

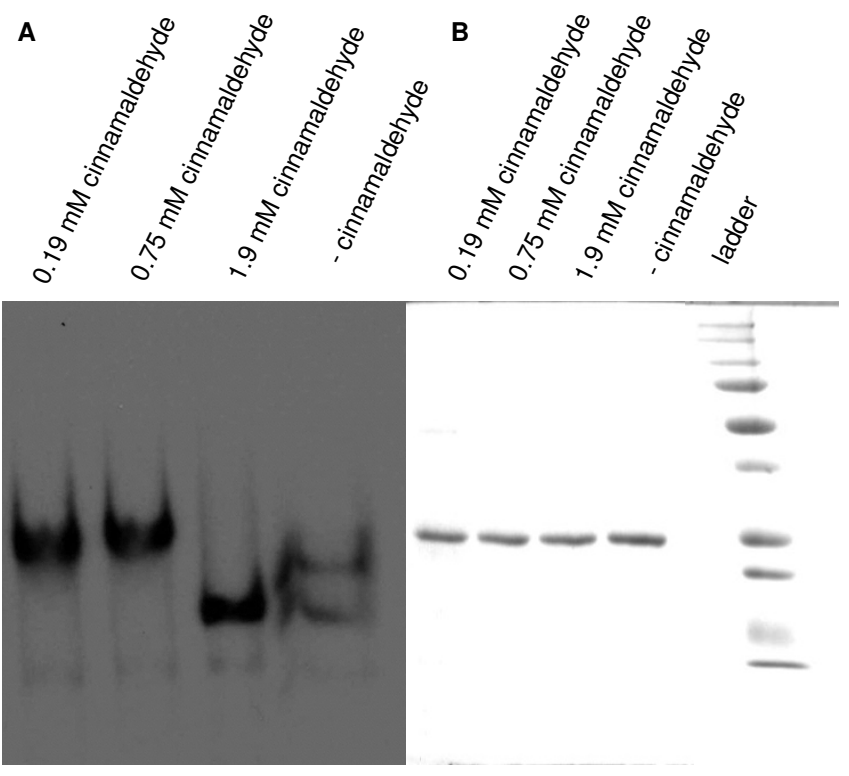

Figure 4

LuxR DNA-binding as determined by mobility shifts and LuxR protein levels as determined by SDS-

PAGE. A. Autoradiograph after 5\% polacrylamide gel electrophoresis of 32P-labelled LuxR promoter DNA containing the LuxR binding sites, mixed with purified LuxR in the presence $(0.19,0.75$ and $1.9 \mathrm{mM})$ and absence of cinnamaldehyde. B. SDS-PAGE of purified LuxR protein in the presence $(0.19$, 0.75 and $1.9 \mathrm{mM}$ ) or absence of cinnamaldehyde. furanone concentrations and may be due to aspecific interactions with DNA and/or protein, although the exact reasons for this remain unknown (C. Miyamoto, unpublished data). Purified LuxR was also used to test whether cinnamaldehyde resulted in protein degradation. Three samples of LuxR containing varying amounts of cinnamaldehyde $(0.19,0.75$ and $1.9 \mathrm{mM})$ and an untreated control were stained following electrophoresis on a $10 \%$ SDS-PAGE gel and were shown not to have been affected by cinnamaldehyde (Fig. 4b). To test whether the DNAbinding ability was also altered in vivo, lysates of Vibrio harveyi cells that were grown in the presence and absence of various cinnamaldehyde concentrations were also tested for their ability to cause a mobility shift of LuxR DNA (data not shown). Surprisingly, no effects were observed with concentrations $<1 \mathrm{mM}$. Using $1 \mathrm{mM}$ cinnamaldehyde, there was about 4-fold less shift of LuxR DNA for the same amount of total protein in the lysate of Vibrio harveyi BB120 treated with cinnamaldehyde. There are several possible explanations for this apparent contradiction in terms of cinnamaldehyde concentrations required to cause a band shift. First of all, there may be considerable differences between the extra- and intracellular cinnamaldehyde concentrations, possibly explaining why we observed a shift with $0.19 \mathrm{mM}$ cinnamaldehyde when purified LuxR protein was used but that higher concentrations were required when cell lysates were used. Secondly, there are no data on how much inhibition of binding of LuxR to its promotor is required in order to observe phenotypic changes (e.g. changes in bioluminescence). It may very well be that relatively minor changes in LuxR DNA binding (caused by relatively low cinnamaldehyde concentrations) are sufficient to cause reductions in bioluminescence but would go unnoticed in the gel shift assay. Combined, our data indicate that in the presence of cinnamaldehyde binding of the transcriptional regulator LuxR to its promoter sequence is affected, while leaving the protein intact. However, further research is needed to explain the differences between the in vitro and in vivo situation in terms of the cinnamaldehyde concentration required to observe this effect. Interestingly, the best-studied QS inhibitors, halogenated furanones, also interfere with binding of LuxR to its promoter sequence without degrading the protein [26].

Effect of cinnamaldehyde and cinnamaldehyde derivatives on Vibrio anguillarum protease and pigment production Cinnamaldehyde and 2- $\mathrm{NO}_{2}$-cinnamaldehyde were found to decrease protease activity by $34 \pm 2 \%$ and $49 \pm$ $5 \%$, respectively after $24 \mathrm{~h}$ (Fig. 5). 4-MeO-cinnamaldehyde was the only other cinnamaldehyde derivative to cause a significant decrease in protease activity $(25 \pm 6 \%)$ (Fig. 5). A time dependent inhibition of pigment production was found for cinnamaldehyde and 2- $\mathrm{NO}_{2}$-cinnamaldehyde. After $48 \mathrm{~h}$, inhibition in pigment 


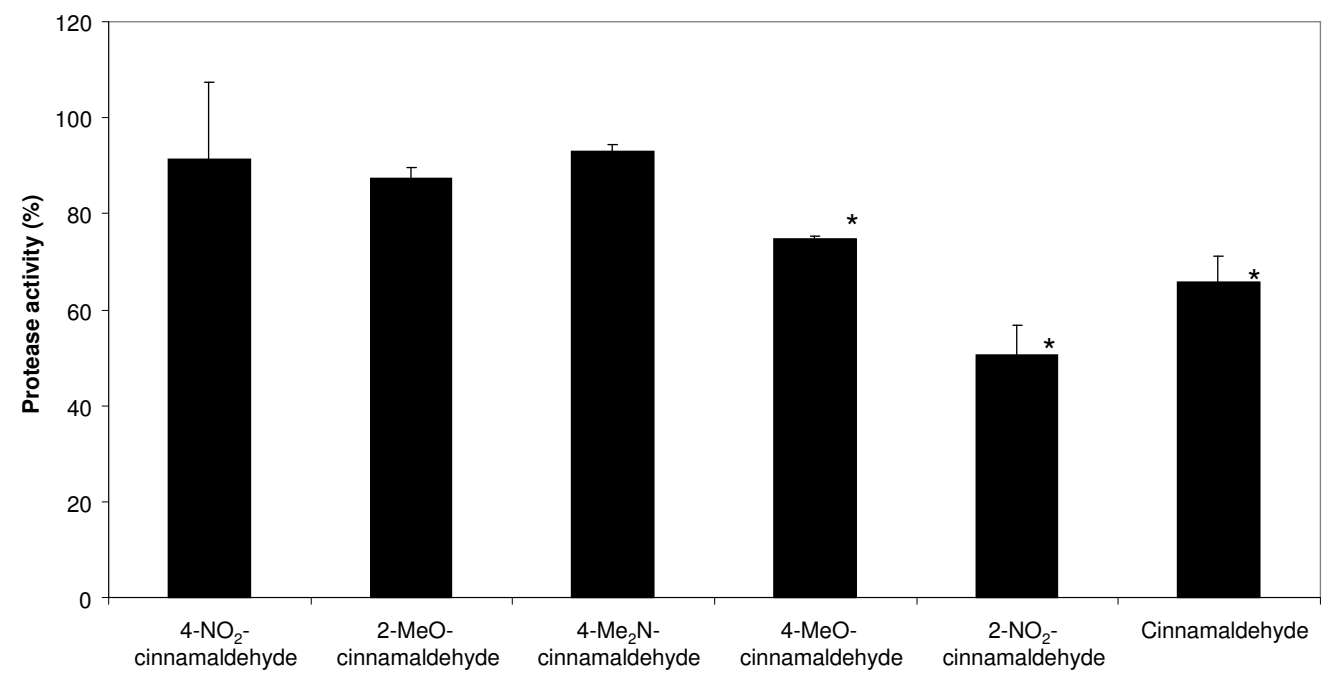

Figure 5

Effect of cinnamaldehyde and cinnamaldehyde derivatives on the protease activity of Vibrio anguillarum LMG 44 I I. Cinnamaldehyde and cinnamaldehyde derivatives were tested at $100 \mu \mathrm{M}$, except $4-\mathrm{NO}_{2}$-cinnamaldehyde $(25 \mu \mathrm{M})$. The effect of cinnamaldehyde or cinnamaldehyde derivatives on protease activity was compared to an untreated control. The error bars represent the standard deviation. *: Signal significantly different from the control $(p<0.05)$.

production was $25 \pm 7 \%$ and $40 \pm 2 \%$ for cinnamaldehyde and $2-\mathrm{NO}_{2}$-cinnamaldehyde (Fig. 6). In contrast, none of the other cinnamaldehyde derivatives were able to signif- icantly reduce pigment production after $48 \mathrm{~h}$ (data not shown). Previously, it was shown that several virulence factors in Vibrio anguillarum, including pigment and pro-

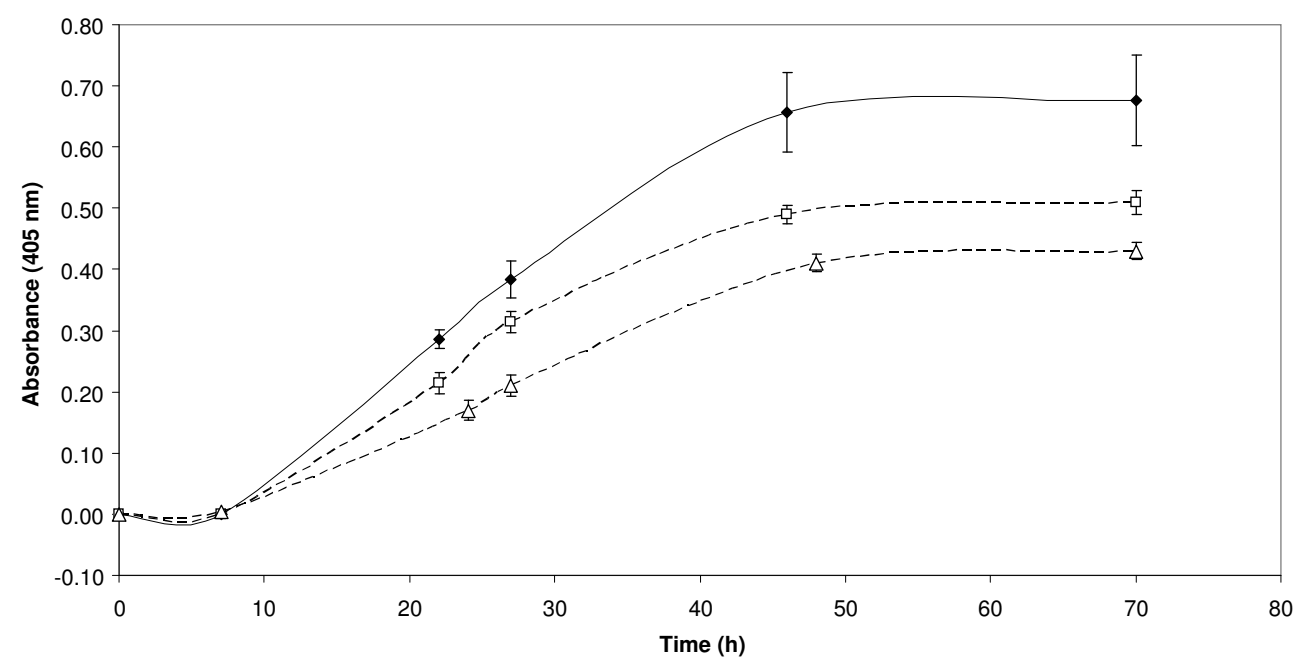

Figure 6

Effect of cinnamaldehyde and 2-NO $\mathrm{NO}_{2}$-cinnamaldehyde on the pigment production of Vibrio anguillarum LMG 44 I I. Cinnamaldehyde and 2-NO $\mathrm{NO}_{2}$-cinnamaldehyde were tested at $100 \mu \mathrm{M}$. Vibrio anguillarum LMG 44II was allowed to produce pigment in the absence (solid symbol) or presence of cinnamaldehyde (open symbol, square) or 2-NO (open symbol, triangle). Three $\mathrm{ml}$ samples were taken at multiple time points. The effect of cinnamaldehyde or $2-\mathrm{NO}_{2}-\mathrm{cin}-$ namaldehyde on pigment production was estimated by measuring the absorbance at $405 \mathrm{~nm}$. The error bars represent the standard deviation. 
tease production, were regulated by QS. It was found that a mutation in vanT (the luxR homologue in Vibrio anguillarum) resulted in a significant decrease in total protease activity due to loss of expression of the metalloprotease EmpA [16]. Loss of protease activity could have several implications for the virulence of Vibrio spp. The protease Vvp of Vibrio vulnificus, which is homologous to EmpA, is thought to play an essential role in the colonisation of mucosal surfaces [31]. In addition, EmpA protease from Vibrio anguillarum is important for virulence during infection of the Atlantic salmon (Salmo salar) and contributes to hemorrhagic skin damage $[32,33]$. Several other phenotypes, including pigment production, were also found to be affected in a Vibrio anguillarum vanT mutant [16].

\section{Effect of cinnamaldehyde and cinnamaldehyde derivatives on biofilm formation}

Cinnamaldehyde was previously shown to inhibit Escherichia coli biofilms. Since cinnamaldehyde significantly reduced swimming motility in Escherichia coli it was hypothesized that reduced biofilm formation could be explained in part by an inability of the strain to reach the substratum [34]. However it should be noticed that no link with QS was described and cinnamaldehyde was used in high concentrations (> $2000 \mu \mathrm{M}$ ). Cinnamaldehyde and some cinnamaldehyde derivatives decreased biofilm formation in Vibrio anguillarum LMG 4411 and Vibrio vul- nificus LMG 16867 (Fig. 7). Cinnamaldehyde reduced total biomass (as measured by crystal violet staining, CV) with $26 \pm 7 \%$ and $27 \pm 13 \%$ in Vibrio anguillarum LMG 4411 and Vibrio vulnificus LMG 16867, respectively. 2$\mathrm{NO}_{2}$-cinnamaldehyde and 4-MeO-cinnamaldehyde resulted in a significant decrease in biomass of Vibrio anguillarum LMG 4411 (decrease of $34 \pm 16 \%$ and $20 \pm$ $12 \%$, respectively). No effect of cinnamaldehyde derivatives on Vibrio vulnificus LMG 16867 biomass was observed (Fig. 7). The cell-viability assay revealed no significant decrease in the number of metabolically active cells in Vibrio anguillarum LMG 4411 and Vibrio vulnificus LMG 16867 biofilm following treatment. In summary, cinnamaldehyde has an effect on total biofilm biomass but not on the number of viable cells. This suggests that cinnamaldehyde may have an effect on the production and/or accumulation of the exopolysaccharide (EPS) matrix (which is also stained with $\mathrm{CV}$ ). To investigate this hypothesis, EPS was stained using Calcofluor white. Calcofluor white is a fluorescent dye which binds $\beta 1-3$ and $\beta 1-4$ carbohydrate linkages and which has been used to study EPS in a variety of organisms [35-37]. The staining was carried out on biofilms treated with cinnamaldehyde as this compound overall had most effect on biofilm biomass as assessed using CV. The use of cinnamaldehyde resulted in a lower fluorescent signal compared to an untreated control $(81 \pm 13 \%$ and $69 \pm 27 \%$ in Vibrio

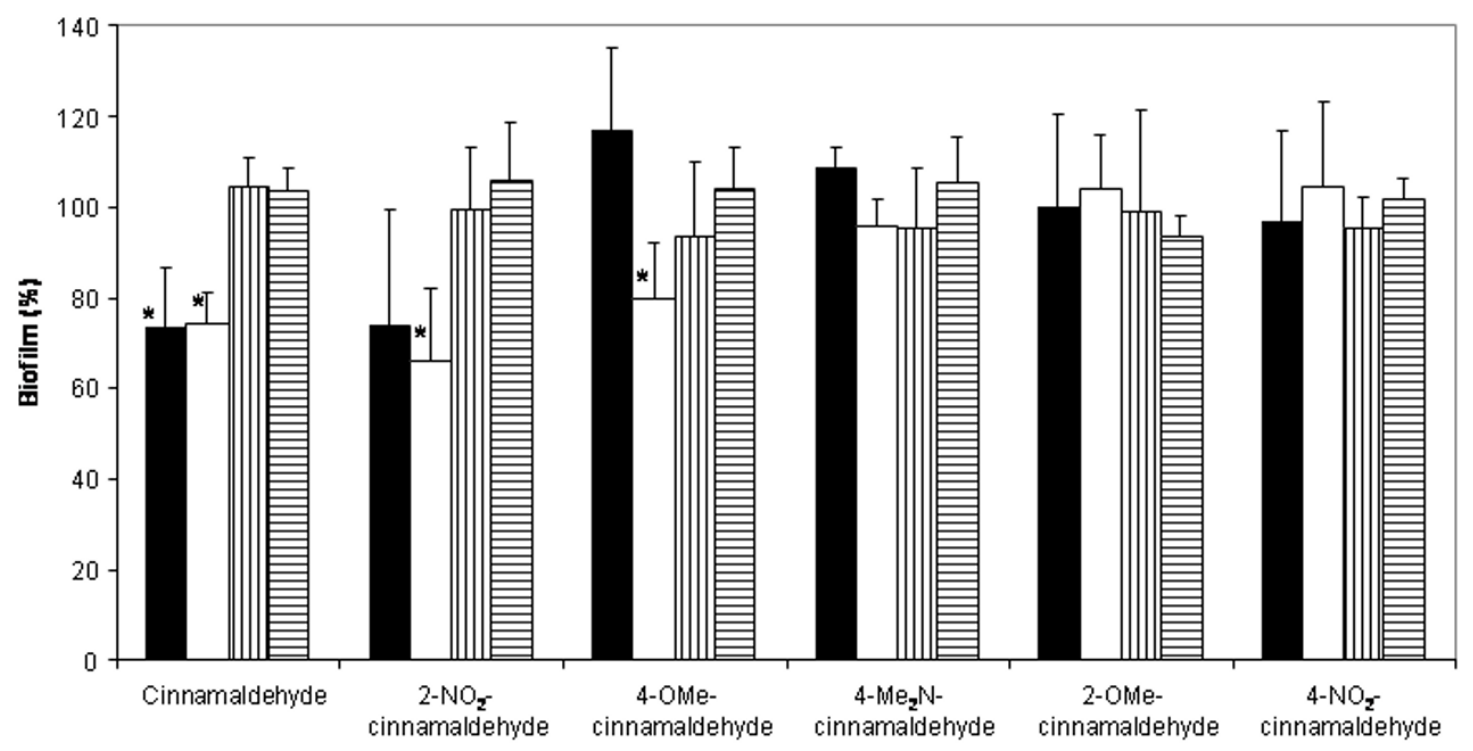

Figure 7

Effect of cinnamaldehyde and cinnamaldehyde derivatives on Vibrio spp. biofilms. Biomass was quantified through CV staining. Cell-viability was quantified through CTB staining. CV signals are presented as a percentage compared to $100 \%$ control not receiving treatment (black bars = Vibrio vulnificus; white bars = Vibrio anguillarum). CTB signals are presented as a percentage compared to a $100 \%$ control not receiving treatment (vertical striped bars = Vibrio vulnificus; horizontal striped bars $=$ Vibrio anguillarum). *: Signal significantly different compared to $100 \%$ control $(p<0.05)$. 
anguillarum LMG 4411 and Vibrio vulnificus LMG 16867, respectively). These data support the hypothesis that the effect of cinnamaldehyde on biofilm formation can be explained by reduced EPS production and/or accumulation.

\section{Protection of Artemia from Vibrio harveyi}

For many pathogenic Vibrio spp., the production of protease, pigment and their capacity to form biofilms contribute to their virulence [31-33]. We investigated the ability of cinnamaldehyde and $2-\mathrm{NO}_{2}$-cinnamaldehyde, the two most active inhibitors, to protect Artemia shrimp against the virulent Vibrio harveyi BB120 strain. To this end, we followed the survival of Artemia after exposure to Vibrio harveyi BB120, with and without addition of compounds (Fig. 8). Cinnamaldehyde and 2- $\mathrm{NO}_{2}$-cinnamaldehyde alone had no effects on Artemia shrimp (data not shown). As expected, high mortality rates were observed when exposing Artemia to Vibrio harveyi BB120. In contrast, cinnamaldehyde and $2-\mathrm{NO}_{2}$-cinnamaldehyde were able to completely protect Artemia against virulent Vibrio harveyi BB120 when used at concentrations of $100 \mu \mathrm{M}$ and $150 \mu \mathrm{M}$ (Fig. 8). At these concentrations, there was no effect on the growth of Vibrio harveyi BB120, ruling out that the protective effect of cinnamaldehyde and 2- $\mathrm{NO}_{2}-$ cinnamaldehyde was due to inhibition of the bacterial pathogen. These results suggest that cinnamaldehyde and cinnamaldehyde derivatives may be useful as antipathogenic compounds.

\section{Effect of cinnamaldehyde on the starvation response}

The effect of cinnamaldehyde on the starvation response of Vibrio vulnificus LMG 16867 and Vibrio anguillarum LMG 4411 was investigated. In the control experiment no decrease in the number of culturable cells after $24 \mathrm{~h}$ of starvation was observed (Fig. 9). Upon treatment with cinnamaldehyde, however, cell numbers were significantly reduced $(53 \pm 3 \%$ and $57 \pm 7 \%$ for Vibrio vulnificus LMG 16867 and Vibrio anguillarum LMG 4411, respectively) (p $<0.05)$. After $48 \mathrm{~h}$, cell numbers were even further reduced in the cinnamaldehyde treated cultures $(87 \pm 3 \%$ and $63 \pm 18 \%$ for Vibrio vulnificus LMG 16867 and Vibrio anguillarum LMG 4411, respectively), while there was only a $77 \pm 5 \%$ and $4 \pm 28 \%$ reduction in number of culturable cells in the control for Vibrio vulnificus LMG 16867 and Vibrio anguillarum LMG 4411, respectively. Bacteria are known for their ability to survive and respond to changes in their surroundings. One of these adaptations is the starvation response found in many marine bacteria. Vibrio spp. are known to survive for a long time without the addition of supplemental nutrition and this starvation response allows cells to survive adverse conditions. QS is thought to play a role in this response to stress conditions [38]. Our data indicate that inhibition of AI-2 based QS

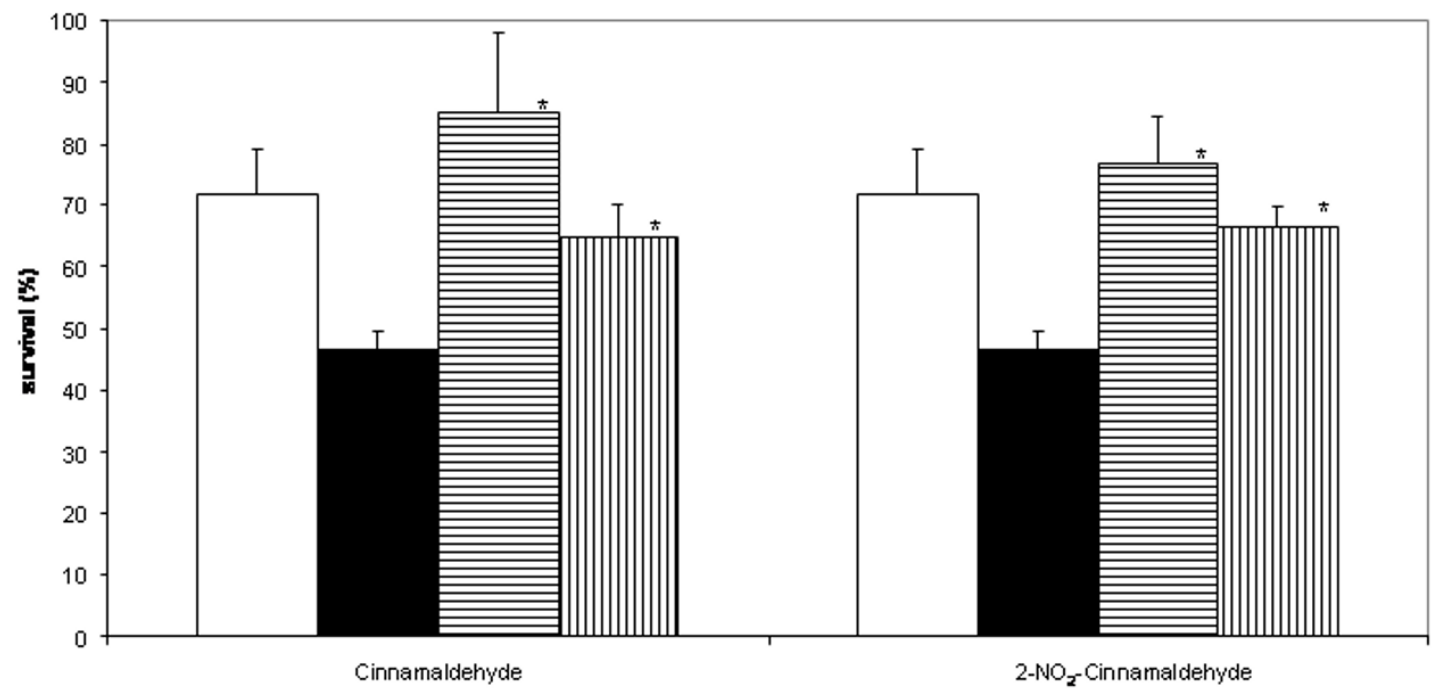

\section{Figure 8}

Effect of cinnamaldehyde and 2- $\mathrm{NO}_{2}$-cinnamaldehyde on the survival of Artemia. White bars represent the survival of Artemia without challenge with Vibrio harveyi BB I20. Black bars represent the percentage survival of Artemia after challenge with Vibrio harveyi BBI20 in untreated conditions. Striped bars represent the percentage of survival of Artemia after challenge with Vibrio harveyi BBI 20 when treated with cinnamaldehyde or 2- $\mathrm{NO}_{2}$-cinnamaldehyde (horizontal: $100 \mu M$ stripes; vertical stripes: I50 $\mu \mathrm{M}$, respectively). *: Survival significantly different from the treatment with pathogen alone $(\mathrm{P}<0.0 \mathrm{I})$. 


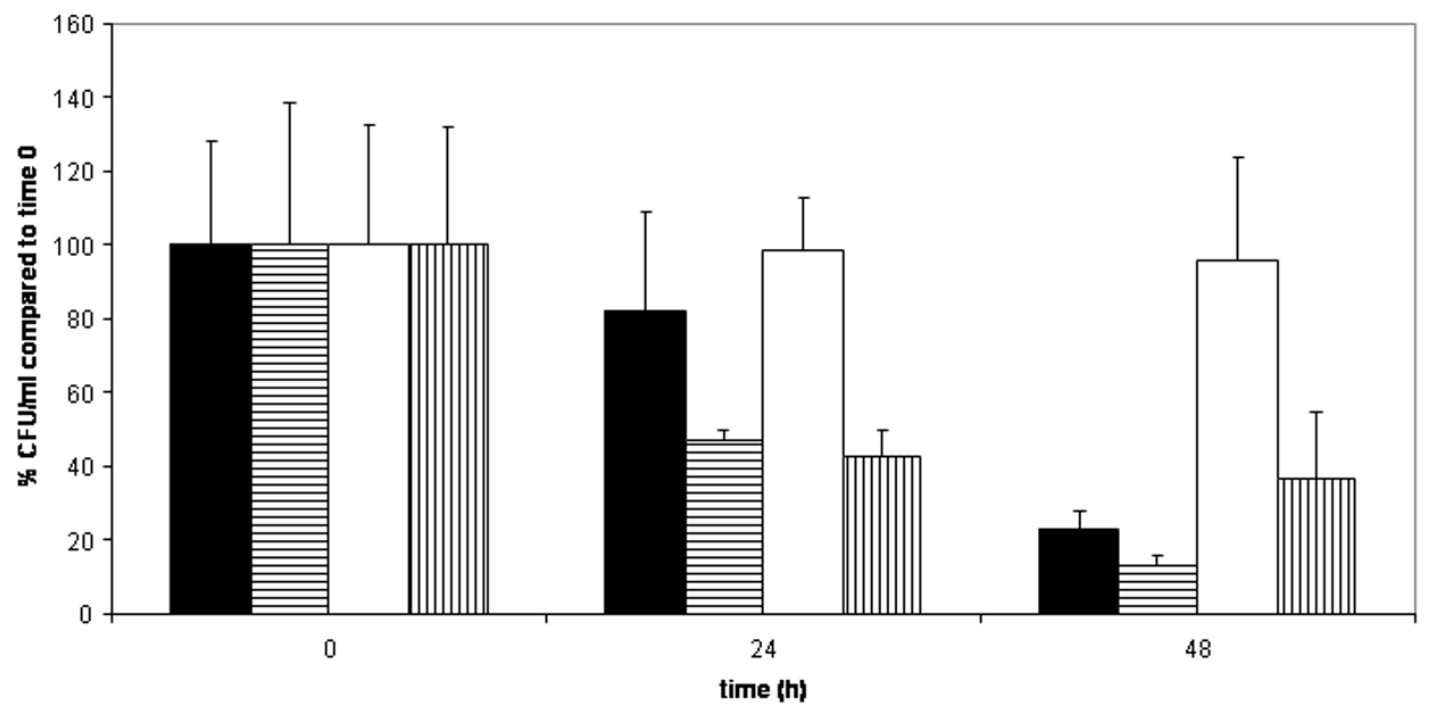

Figure 9

Effect of cinnamaldehyde on Vibrio spp. starvation response. The cells were allowed to starve in the presence (horizontal striped bars = Vibrio vulnificus; vertical striped bars $=$ Vibrio anguillarum) and absence (black bars = Vibrio vulnificus; white bars $=$ Vibrio anguillarum) of cinnamaldehyde. The number of CFU $/ \mathrm{ml}$ was determined after $24 \mathrm{~h}$ and $48 \mathrm{~h}$ on TSA plates containing $2 \% \mathrm{NaCl}$. Data are presented as a percentage of the initial count. Error bars represent standard deviations.

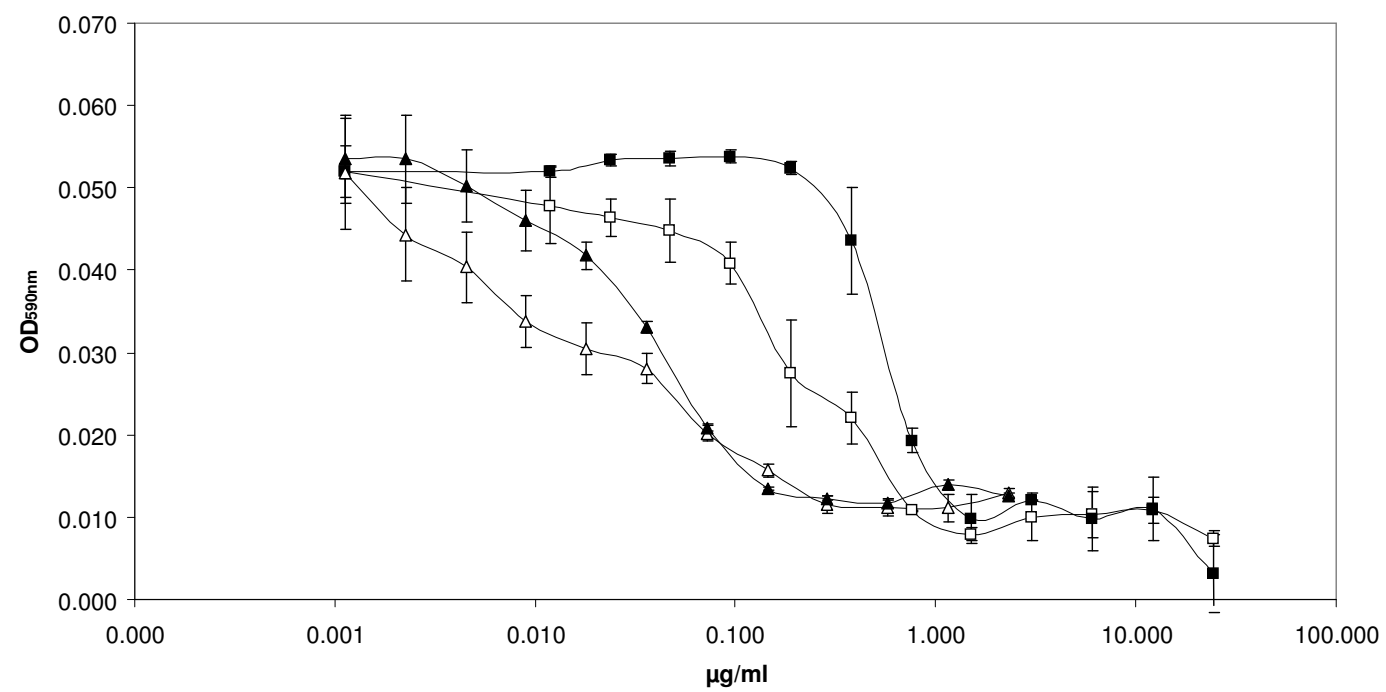

\section{Figure 10}

Effect of cinnamaldehyde on antibiotic susceptibility of Vibrio vulnificus LMG 16867. Effects of chloramphenicol (squares) and doxycycline (triangles) on the growth of Vibrio vulnificus LMGI6867 in the presence (open symbols) and absence (solid symbols) of cinnamaldehyde $(100 \mu \mathrm{M})$ are presented. The absorbance at $590 \mathrm{~nm}$ was measured after $24 \mathrm{~h}$ of growth. Error bars represent standard deviations. 
suppresses the starvation response and makes cells more susceptible to starvation-associated stress conditions. This is in agreement with a previously published study [17] in which starvation survival in Vibrio vulnificus was reduced by mutation of LuxR in the QS system and by halogenated furanones.

\section{Effect of cinnamaldehyde on antibiotic susceptibility}

We have examined the association between QS and antibiotic susceptibility in two Vibrio spp. Two antibiotics with a different mode of action were chosen. Chloramphenicol, previously used as prophylactic in aquaculture, targets the 50S ribosomal subunit $[39,40]$. Doxycycline, an antibiotic targeting the $30 \mathrm{~S}$ ribosomal subunit, is the recommended antibiotic therapy for Vibrio vulnificus infections [41]. Vibrio vulnificus LMG 16867 showed an increased antibiotic susceptibility when treated with cinnamaldehyde (Fig. 10). This difference was most pronounced when using chloramphenicol. In contrast, in Vibrio anguillarum LMG 4411, no differences were observed between cinnamaldehyde treatment and control (data not shown). Previously, it was found that QS inhibition could alter the susceptibility of a strain towards antimicrobial agents. Vibrio cholerae strains with various mutations in the AI-2 signal transduction system appeared to be more sensitive to treatment with hydrogen peroxide [42]. Similarly, a Streptococcus anginosus LuxS mutant was found to be more susceptible towards ampicillin and erythromycin than the wild type strain [43].

\section{Conclusion}

Cinnamaldehyde and several derivatives were shown to interfere with AI-2 based QS by decreasing the ability of LuxR to bind to its target promoter sequence. These compounds, used in sub-inhibitory concentrations, did not only affect in vitro the production of multiple virulence factors and biofilm formation, but also reduced in vivo the mortality of Artemia shrimp exposed to Vibrio harveyi BB120. In addition, cinnamaldehyde reduced the ability to cope with stress factors like starvation and exposure to antibiotics. Our results indicate that cinnamaldehyde and cinnamaldehyde derivatives are potentially useful antipathogenic lead compounds for treatment of vibriosis.

\section{Methods}

\section{Cinnamaldehyde and cinnamaldehyde derivatives}

Cinnamaldehyde (Sigma-Aldrich, Bornem, Belgium) and cinnamaldehyde derivatives [4-MeO-cinnamaldehyde (VWR International, West Chester, USA), 2-MeO-cinnamaldehyde (Wako Pure Chemical Industries, Osaka, Japan), 4- $\mathrm{NO}_{2}$-cinnamaldehyde, 2- $\mathrm{NO}_{2}$-cinnamaldehyde and $4-\mathrm{Me}_{2} \mathrm{~N}$-cinnamaldehyde (Acros Organics, Geel, Belgium)] (Fig. 1), were diluted in DMSO $(0.5 \% \mathrm{v} / \mathrm{v})$. The stock solutions were stored at $-20^{\circ} \mathrm{C}$. Control solutions
(CS) contained the same amount of DMSO, without cinnamaldehyde or cinnamaldehyde derivatives.

\section{Bacterial strains, plasmid and growth conditions}

The strains and plasmid used in this study are shown in Table 1. All strains were routinely cultured in MarineBroth (MB) (BD, Sparks, MD, USA) in the presence of appropriate antibiotics, except for Escherichia coli DH5 $\alpha$ and K12, which were grown in Luria-Bertani broth (LB) (BD). The medium was supplemented with $100 \mu \mathrm{g} / \mathrm{ml}$ ampicillin (Sigma-Aldrich) for Escherichia coli DH5 $\alpha$ containing the pBluelux plasmid. Vibrio anguillarum LMG 4411, Vibrio vulnificus LMG 16867 and the various Vibrio harveyi strains were cultured overnight at $30^{\circ} \mathrm{C}$ on a rotary shaker. Escherichia coli DH5 $\alpha$ and K12 were cultured overnight at $30^{\circ} \mathrm{C}$ and $37^{\circ} \mathrm{C}$, respectively, without agitation. Minimal inhibitory concentrations were determined for each compound by using a microdilution assay in flat bottomed 96-well microtiter plates (TPP, Trasadingen, Switzerland), using $\mathrm{MB}$ and $\mathrm{LB}$ medium for all vibrios and both Escherichia coli strains, respectively. The plates were incubated for $24 \mathrm{~h}$ and the absorption at $590 \mathrm{~nm}$ was measured using a Victor Wallac ${ }^{2}$ multilabel counter (Perkin Elmer Life and Analytical Sciences, Boston, MA, USA).

\section{Effect of cinnamaldehyde and cinnamaldehyde derivatives on bioluminescence}

To determine whether any of the compounds had an effect on bioluminescence not related to inhibition of QS, Escherichia coli DH5 $\alpha$ was transformed with the pBluelux plasmid, containing luxCDABE under control of a lacZ promoter and the effect on bioluminescence was measured. The pBluelux plasmid was transformed in Escherichia coli DH5 $\alpha$ as follows. Overnight cultures were suspended in a $50 \mathrm{mM} \mathrm{CaCl}_{2}$ solution at $0^{\circ} \mathrm{C}$. The pBluelux plasmid was added and the solution was incubated for $15 \mathrm{~min}$. After this, the solution was transferred to $42^{\circ} \mathrm{C}$ for $90 \mathrm{sec}$ and the cell suspension was plated on Trypton soy agar (TSA) (Oxoid, Basingstoke, Hampshire, UK) containing $100 \mu \mathrm{g} / \mathrm{ml}$ ampicillin (Sigma-Aldrich) for selection of transformants. For the bioluminescence assay an overnight culture was diluted to $\mathrm{OD}_{590 \mathrm{~nm}}$ of approximately 0.1 and $100 \mu \mathrm{l}$ of cell suspension was added to each well of a black 96-well microtiter plate (Perkin Elmer). The effect on bioluminescence for the active compounds was compared to controls not receiving the active molecules.

\section{Bioassay for LuxS inhibition}

In order to determine whether any of the compounds tested had an effect on production of AI-2, AI-2 activity was measured in supernatants of Escherichia coli K12 cultures grown for $16 \mathrm{~h}$ with or without compounds. Overnight cultures of Escherichia coli K12 were centrifuged ( $5000 \mathrm{rpm}, 5 \mathrm{~min}$, room temperature) and filter sterilised (0.22 $\mu \mathrm{m}$, Whatman GmbH, Dassel, Germany). The 
Table I: Strains and plasmid used in this study.

\begin{tabular}{|c|c|c|}
\hline Strain/plasmid & Relevant features & Reference or source \\
\hline \multicolumn{3}{|c|}{ Vibrio harveyi strains } \\
\hline $\mathrm{BB} \mid 20$ & Wild type from which strains BBI52, BBI70, MM30, JAF553, JAF483 and BNL258 are derived & [9] \\
\hline $\mathrm{BB} \mid 70$ & $\operatorname{luxN}:: \operatorname{Tn} 5$ & [7] \\
\hline MM30 & luxS::Tn5 & {$[10]$} \\
\hline JAF553 & luxU H58A linked to $\mathrm{Kan}^{\mathrm{R}}$ & [48] \\
\hline JAF483 & luxO D47A linked to KanR & {$[14]$} \\
\hline BNL258 & hfq::Tn5lacZ & [49] \\
\hline
\end{tabular}

Vibrio anguillarum

\begin{tabular}{|c|c|c|}
\hline LMG 44II & Isolated from young sea trout (Salmo trutta) & BCCM/LMG \\
\hline \multicolumn{3}{|l|}{ Vibrio vulnificus } \\
\hline LMG I6867 & Isolated from tankwater from eelfarm & BCCM/LMG \\
\hline \multicolumn{3}{|c|}{ Escherichia coli strains } \\
\hline $\mathrm{DH} 5 \alpha$ & Al-2 - strain & {$[23]$} \\
\hline $\begin{array}{l}\text { KI2 } \\
\text { ATCC } 25404\end{array}$ & $\mathrm{Al}-2^{+}$strain & [23] \\
\hline \multicolumn{3}{|l|}{ Plasmid } \\
\hline pBluelux & pBluelux polylinker and luxCDABE & S. Atkinson \\
\hline
\end{tabular}

BCCM/LMG: Belgian Co-ordinated Collections of Micro-organisms/Laboratory of Microbiology collection (Ghent University, Belgium); ATCC: American Type Culture Collection

supernatants were used immediately or stored at $-20^{\circ} \mathrm{C}$. AI-2 levels were determined in a Vibrio harveyi BB170 assay as described previously [21]. In brief, an overnight culture of the reporter strain was diluted 1:5000 into fresh sterile $\mathrm{MB}$ medium and $90 \mu \mathrm{l}$ of this cell suspension was added to the wells of a black 96 -well microtiter plate (Perkin Elmer). Ten $\mu \mathrm{l}$ of the appropriate sterile supernatants was then added to the wells, the microtiter plates were incubated at $30^{\circ} \mathrm{C}$ and bioluminescence was measured hourly using a Wallac Victor ${ }^{2}$ multilabel counter (Perkin Elmer). Bioluminescence was expressed as the fraction of bioluminescence measured in the positive control reaction. Confirmation of these results was obtained using Vibrio harveyi MM30, a $\Delta$ LuxS mutant, instead of Vibrio harveyi $\mathrm{BB} 170$. The effect on bioluminescence for the active compounds was compared to controls not receiving the active molecules.

\section{Other Vibrio harveyi bioassays}

Using Vibrio harveyi strains BB120, JAF553, JAF483 and BNL258, we determined whether the molecular target of our compounds was located in the AI-2 signalling transduction pathway. The bioluminescence assay as described above was used with minor modifications. In brief, the positive control reaction received $10 \mu \mathrm{l}$ of Escherichia coli K12 supernatant, without addition of the test molecule. Negative control reactions received $10 \mu \mathrm{l}$ sterile MBmedium. Other wells received $10 \mu \mathrm{l}$ of Escherichia coli K12 supernatants (containing AI-2) and appropriate amounts of the test molecule.

\section{Effect of cinnamaldehyde on LuxR protein levels and DNA-binding activity}

Mobility shift assays and SDS-PAGE assays were performed as described previously [26] with minor modifications. Vibrio harveyi BB120 cells were grown in the presence and absence of cinnamaldehyde and all cell lysates were taken at different optical densities $\left(\mathrm{OD}_{600 \mathrm{~nm}}\right.$ $=1.2,1.6,1.8$ and 2.1). Previously purified LuxR [44] was used for mobility shift and SDS-PAGE assay. For SDSPAGE the following protein standard (Bio-rad) was used: $250,150,100,75,50,37,25,20,15$ and $10 \mathrm{kDa}$.

\section{Quantification of protease activity}

Vibrio anguillarum LMG 4411 was grown overnight in MB. Protease activity was quantified following inoculation of cultures into medium containing 2.0\% Bacto agar (Oxoid), 2.0\% NaCl (Novolab, Geraardsbergen, Belgium) 
and $3.0 \%$ Skim Milk powder (Oxoid). Appropriate amounts of test compounds and CS were added to the mixtures, $0.5 \mathrm{ml}$ of these mixtures was added to the wells of a 24-well microtiter plate (TPP, Trasadingen, Switzerland) and the plate was incubated at $30^{\circ} \mathrm{C}$. Clearing was measured spectrophotometrically with a Wallac Victor ${ }^{2}$ multilabel counter after $24 \mathrm{~h}$.

\section{Quantification of pigment production}

Vibrio anguillarum LMG 4411 was grown overnight at $30^{\circ} \mathrm{C}$ in $\mathrm{MB}$. The overnight culture was then diluted to $\mathrm{OD}_{590 \mathrm{~nm}}=0.05$ in Tryptone Soy Broth (TSB) (Oxoid) containing $5 \mathrm{mM}$ L-tyrosine (Sigma-Aldrich) with or without test compound and incubated at $30^{\circ} \mathrm{C}$ with shaking. At various time points, $3 \mathrm{ml}$ samples were taken from the cultures and supernatants were collected by centrifugation (5000 rpm, $4 \mathrm{~min}$, room temperature), followed by filter sterilisation $(0.22 \mu \mathrm{m})$. Pigment production was followed by measuring the absorbance at $405 \mathrm{~nm}$.

\section{Biofilm formation assay}

Vibrio anguillarum LMG 4411 (doubling time $\mathrm{T}_{\mathrm{d}}$ : $3.2 \mathrm{~h}$ ) and Vibrio vulnificus LMG $16867\left(\mathrm{~T}_{\mathrm{d}}: 5.3 \mathrm{~h}\right)$ were grown overnight in $\mathrm{MB}$, centrifuged, resuspendend in double concentrated Marine Broth $(2 \mathrm{xMB})$ and diluted to an $\mathrm{OD}_{590 \mathrm{~nm}}=0.1$ in $2 \mathrm{xMB}$. Fifty $\mu$ l of the diluted bacterial suspension was transferred to the wells of a round-bottomed 96-well microtiter plate (TPP). Negative controls received $50 \mu \mathrm{l}$ of CS. Positive controls received $50 \mu \mathrm{l}$ of the test compound in appropriate concentrations. Bacteria were allowed to adhere and grow without agitation for 4 $\mathrm{h}$ at $30^{\circ} \mathrm{C}$. After $4 \mathrm{~h}$, plates were emptied and washed with sterile physiological saline (PS). After this washing step, negative control wells were filled with $50 \mu \mathrm{L} 2 \mathrm{xMB}$ and 50 $\mu \mathrm{l} \mathrm{CS}$. Other wells were filled with $50 \mu \mathrm{l} 2 \mathrm{xMB}$ and $50 \mu \mathrm{l}$ compound solution and the plate was incubated for $24 \mathrm{~h}$ at $30^{\circ} \mathrm{C}$. Biofilm biomass was quantified by crystal violet (CV) staining, as described previously [45]. In brief, plates were rinsed with sterile PS, biofilms were fixed by adding $100 \mu \mathrm{l} 99 \%$ methanol for $15 \mathrm{~min}$, after which the methanol was removed and plates were air-dried. Biofilms were then stained with $100 \mu \mathrm{l} \mathrm{CV}$ (Pro-lab Diagnostics, Richmond Hill, ON, Canada). After $20 \mathrm{~min}, \mathrm{CV}$ was removed and wells were filled with $150 \mu \mathrm{l} 33 \%$ acetic acid (SigmaAldrich). The absorbance was measured at $590 \mathrm{~nm}$ using a Wallac Victor $^{2}$ multilabel counter and results were expressed as the percentages compared to the signal of the control not receiving treatment. For quantification of the number of metabolically active (i.e. living) cells in the biofilm, a resazurin assay was used [45]. In brief, wells were rinsed after $24 \mathrm{~h}$ biofilm formation and $100 \mu \mathrm{l}$ PS was added, followed by addition of $20 \mu$ l CellTiter-Blue (CTB) (Promega, Leiden, The Netherlands) solution. After $60 \mathrm{~min}$, fluorescence $\left(\mathrm{ex}_{560 \mathrm{~nm}} / \mathrm{em}_{590 \mathrm{~nm}}\right)$ was measured using a Wallac Victor ${ }^{2}$ multilabel counter. For the quanti- fication of EPS, a Calcofluor white staining (SigmaAldrich) was used. In brief, wells were rinsed after $24 \mathrm{~h}$ biofilm formation and $100 \mu \mathrm{l}$ phosphate buffered saline (PBS) containing $0.5 \mu \mathrm{l} 5 \mathrm{mM}$ CFW was added to the wells. After $60 \mathrm{~min}$, fluorescence $\left(\mathrm{ex}_{405 \mathrm{~nm}} / \mathrm{em}_{500 \mathrm{~nm}}\right)$ was measured using a Wallac Victor ${ }^{2}$ multilabel counter.

\section{Artemia Challenge tests}

All experiments were performed with high quality hatching cysts of Artemia franciscana (EG ${ }^{\circledR}$ Type, batch 6940, INVE Aquaculture, Baasrode, Belgium). $200 \mathrm{mg}$ of cysts were hydrated in $18 \mathrm{ml}$ of tap water during $1 \mathrm{~h}$. Sterile cysts and nauplii were obtained via decapsulation as described previously [46]. Challenge tests were performed as described previously [18] with minor modifications. Briefly, after hatching, groups of 20 nauplii were transferred to new sterile $50 \mathrm{ml}$ tubes that contained $20 \mathrm{ml}$ of $0.22 \mu \mathrm{m}$ filtered and autoclaved artificial seawater. Vibrio harveyi BB120 was washed in filtered and autoclaved artificial seawater after incubation and added to the Artemia culture water at a concentration of approximately $10^{5}$ $\mathrm{CFU} / \mathrm{ml}$. A suspension of autoclaved LVS3 bacteria in filtered and autoclaved artificial seawater was added as feed in a concentration of approximately $10^{7} \mathrm{CFU} / \mathrm{ml}$ culture water. After the addition of $100 \mu \mathrm{M}$ or $150 \mu \mathrm{M}$ of cinnamaldehyde or 2- $\mathrm{NO}_{2}$-cinnamaldehyde (or an appropriate volume of solvent), the falcon tubes were put back on the rotor and kept at $28^{\circ} \mathrm{C}$. Artemia cultures to which only autoclaved LVS3 bacteria were added were used as controls. The survival of Artemia was scored $48 \mathrm{~h}$ after the addition of the strains. All manipulations were done under a laminar flow hood in order to maintain sterility of the cysts and nauplii. Each treatment was done in triplicate.

\section{Starvation assay}

Vibrio anguillarum LMG 4411 and Vibrio vulnificus LMG 16867 strains were grown overnight in $\mathrm{MB}$, the cells were collected by centrifugation ( $5000 \mathrm{rpm}, 4 \mathrm{~min}$ ), washed in PS and resuspended in artificial seawater (ASW) [47] containing $0.1 \% \mathrm{MB}$ (with and without test compound). These suspensions were incubated at $30^{\circ} \mathrm{C}$ without shaking. At various time points, $1 \mathrm{ml}$ samples were taken and the number of culturable cells was determined by plating serial dilutions on TSA (Oxoid) plates containing 2\% $\mathrm{NaCl}$. Results were expressed as the percentage survival compared to the untreated control.

\section{Effect of cinnamaldehyde on antibiotic resistance}

Fifty $\mu \mathrm{L}$ of double concentrated TSB (2xTSB) containing $4 \% \mathrm{NaCl}$ with or without chlorampenicol (SigmaAldrich) or doxycycline (Sigma-Aldrich) (added in the range of $0.001 \mu \mathrm{g} / \mathrm{ml}-25 \mu \mathrm{g} / \mathrm{ml}$ ) were dispensed into flat-bottomed 96-well microtiter plates (TPP). An equal amount of cinnamaldehyde was added (final concentra- 
tion of $100 \mu \mathrm{M})$. For the controls, equal amounts of CS were added to the wells. Vibrio vulnificus LMG 16867 or Vibrio anguillarum LMG 4411 was added in a final concentration of $10^{5} \mathrm{CFU} / \mathrm{ml}$. The plates were incubated overnight at $30^{\circ} \mathrm{C}$ and growth was evaluated after $24 \mathrm{~h}$ by absorbance measurements at $590 \mathrm{~nm}$ using a Wallac Victor ${ }^{2}$ multilabel counter.

\section{Statistics}

Independent samples t-tests were performed using the SPSS software, version 15.0 (SPSS, Chicago, IL, USA).

\section{Authors' contributions}

GB carried out most of the experiments, analysed the data, provided figures and tables and drafted the manuscript. $\mathrm{TD}$ and $\mathrm{PB}$ carried out the in vivo virulence assay. CM carried out the mobility shift and SDS-PAGE assays. SVC coordinated and participated in the selection of the compounds. TC and HN coordinated the study and helped to draft the manuscript. All authors read and approved the final manuscript.

\section{Acknowledgements}

The authors like to thank Dr. S. Atkinson for kindly providing the pBlueLux plasmid. This work was supported by the 'Instituut voor de aanmoediging van Innovatie door Wetenschap en Technologie in Vlaanderen' (GB) and FWO-Vlaanderen (TC)

\section{References}

I. Austin $B$, Zhang $\mathrm{XH}$ : Vibrio harveyi: a significant pathogen of marine vertebrates and invertebrates. Lett Appl Microbiol 2006 43:119-124.

2. APEC/FAO/NACA/SEMARNAP: Report of a joint APEC/FAO/ NACA/SEMARNAP ad-hoc expert consultation on transboundary aquatic animal pathogen transfer and development of harmonised standards on aquaculture health management. Puerto Vallarta, Jalisco, Mexico . 24-28 july 2000

3. Holmström K, Gräslund S, Wahlström A, Poungshompoo S, Bengtsson $\mathrm{BE}$, Kautsky N: Antibiotic use in shrimp farming and implications for environmental impacts and human health. Int Food Sci Technol 2003, 38:255-266.

4. Tendencia EA, Dela Pena M: Antibiotic resistance of bacteria from shrimp ponds. Aquaculture 200I, 195: I 93-204.

5. Karunasagar I, Pai R, Malahti GR, Karunasagar I: Mass mortality of Penaeus monodon larvae due to antibiotic-resistant Vibrio harveyi infection. Aquaculture 1994, 1 28:203-209.

6. Xavier KB, Bassler BL: LuxS quorum sensing: more than just a numbers game. Curr Opin Microbiol 2003, 6:191-197.

7. Bassler BL, Wright M, Showalter RE, Silverman MR: Intercellular signalling in Vibrio harveyi: sequence and function of genes regulating expression of luminescence. Mol Microbiol 1993 9:773-786.

8. Higgins DA, Pomianek ME, Kraml CM, Taylor RK, Semmelhack MF, Bassler BL: The major Vibrio cholerae autoinducer and its role in virulence factor production. Nature 2007, 450:883-88.

9. Bassler BL, Greenberg EP, Stevens AM: Cross-species induction of luminescence in the quorum-sensing bacterium Vibrio harveyi. J Bacteriol 1997, 179:4043-4045.

10. Surette MG, Miller MB, Bassler BL: Quorum sensing in Escherichia coli, Salmonella typhymurium, and Vibrio harveyi: a new family of genes responsible for autoinducer production. Proc Nat Acad Sci 1999, 96:1639-1644.

II. Miller ST, Xavier KB, Campagna SR, Taga ME, Semmelhack MF, Bassler BL, Hughson FM: Salmonella typhimurium recognizes a chemically distinct form of the bacterial quorum-sensing signal Al-2. Mol Cell 2004, 15:677-687.
12. Milton DL: Quorum sensing in Vibrio spp.: complexity for diversification. Int J Med Microbiol 2006, 296:6I-7I.

13. Bassler BL, Wright M, Silverman MR: Sequence and function of LuxO, a negative regulator of luminescence in Vibrio harveyi. Mol Microbiol 1994, I 2(3):403-4I2.

14. Freeman JA, Bassler BL: A genetic analysis of the function of LuxO, a two component response regulator involved in quorum sensing in Vibrio harveyi. Mol Microbiol 1999, 3 I:665-667.

15. Larsen MH, Blackburn N, Larsen JL, Olsen JE: Influences of temperature, salinity and starvation on the motility and chemotactic response of Vibrio anguillarum. Microbiology 2004, 150:1283-1290.

16. Croxatto A, Chalker VJ, Lauritz J, Jass J, Hardman A, Williams P, Camara M, Milton DL: VanT, a homologue of Vibrio harveyi LuxR, regulates serine, metalloprotease, pigment, and biofilm production in Vibrio anguillarum. J Bacteriol 2002, 184:1617-1629

17. McDougald D, Rice SA, Kjelleberg S: SmcR-dependent regulation of adaptive phenotypes in Vibrio vulnificus. J Bacteriol 200I, 183:758-762.

18. Defoirdt T, Bossier P, Sorgeloos P, Verstraete W: The impact of mutations in the quorum sensing system of Aeromonas hydrophila, Vibrio anguillarum and Vibrio harveyi on their virulence towards gnotobiotically cultured Artemia franciscana. Environ Microbiol 2005, 7: 1239-1247.

19. Lee JH, Rhee JE, Park U, Ju HM, Lee BC, Kim TS, Jeong HS, Choi SH: Identification and functional analysis of Vibrio vulnificus SmcR, a novel global regulator. I Microbiol Biotechnol 2007 I7:325-334.

20. Alfaro JF, Zhang T, Wynn DP, Karschner EL, Zhou ZS: Synthesis of LuxS inhibitors targeting bacterial cell-cell communication. Org Lett 2004, 6:3043-3046.

21. Niu C, Alfre S, Gilbert ES: Subinhibitory concentrations of cinnamaldehyde interfere with quorum sensing. Lett Appl Microbiol 2006, 43:489-494.

22. Novak JS, Fratamico PM: Evaluation of ascorbic acid as a quorum sensing analogue to control growth, sporulation, and enterotoxin production in Clostridium perfringens. J Food $\mathrm{Sci}$ 2004, 69:72-78

23. Ren D, Bedzyk LA, Ye RW, Thomas SM, Wood TK: Differential gene expression shows natural brominated furanones interfere with the autoinducer-2 bacterial signalling system of Escherichia coli. Biotech Bioeng 2004, 88:630-642.

24. Ren D, Sims J], Wood TK: Inhibition of biofilm formation and swarming of Escherichia coli by (5Z)-4-bromo-5-(bromomethylene)-3-butyl-2-(5H)-furanone. Environ Microbiol 200I, 3:73I-736.

25. Hentzer M, Givskov M: Pharmacological inhibition of quorum sensing for the treatment of chronic bacterial infections. J Clin Invest 2003, I I 2: I 300-1307.

26. Defoirdt T, Miyamoto CM, Wood TK, Meighen EA, Sorgeloos P, Verstraete $W$, Bossier $P$ : The natural furanone (5Z)-4-bromo-5(bromomethylene)-3-butyl-2(5H)-furanone disrupts quorum sensing-regulated gene expression in Vibrio harveyi by decreasing the DNA-binding activity of the transcriptional regulator protein luxR. Environ Microbiol 2007, 9:2486-2495.

27. Defoirdt T, Crab R, Wood TK, Sorgeloos P, Verstraete W, Bossier $P$ : Quorum sensing-disrupting brominated furanones protect the gnotobiotic brine shrimp Artemia franciscana from pathogenic Vibrio harveyi, Vibrio campbellii, and Vibrio parahaemolyticus isolates. Appl Environ Microbiol 2006, 72:6419-6423.

28. Tinh NT, Linh ND, Wood TK, Dierckens K, Sorgeloos P, Bossier P: Interference with the quorum sensing systems in a Vibrio harveyi strain alters the growth rate of gnotobiotically cultured rotifer Brachionus plicatilis. J Appl Microbiol 2007, 103:194-203.

29. Adams TB, Cohen SM, Doull J, Feron VJ, Goodman Jl, Marnett LJ, Munro IC, Portoghese PS, Smith RL, Waddell W], Wagner BM: The FEMA GRAS assessment of cinnamyl derivates used as flavour ingredients. Food Chem Toxicol 2004, 42:157-I85.

30. Friedman M, Kozukue N, Harden LA: Cinnamaldehyde content in foods determined by gas chromatography-mass spectrometry. J Agric Food Chem 2000, 48:5702-5709.

31. Valiente E, Lee CT, Hor LI, Fouz B, Amaro C: Role of the metalloprotease Vvp and the virulence plasmid pR99 of Vibrio vulnificus serovar $E$ in surface colonization and fish virulence. Environ Microbiol 2007, 10:328-338. 
32. Denkin SM, Nelson DR: Regulation of Vibrio anguillarum EmpA metalloprotease expression and its role in virulence. Appl Environ Microbiol 2004, 70:41 93-4204.

33. Miyoshi S: Vibrio vulnificus infection and metalloprotease. J Dermatol 2006, 33:589-595.

34. Niu C, Gilbert ES: Colorometric method for indentifying plant essential oil components that affect biofilm formation and structure. Appl Environ Microbiol 2004, 70:695I-6956.

35. Ledeboer NA, Jones BD: Exopolysaccharide sugars contribute to biofilm formation by Salmonella enterica serovar Typhimurium on Hep-2 cells and chicken intestinal epithelium. J Bacteriol 2005, 187:32|4-3226.

36. Wells DH, Long SR: The Sinorhizobium meliloti stringent response affects multiple aspects of symbiosis. Mol Microbiol 2005, 43: III 5-III27.

37. Zogaj X, Nimtz M, Rohde M, Bokranz W, Romling U: The multicellular morphotypes of Salmonella typhimurium and Escherichia coli produce cellulose as the second component of the extracellular matrix. Mol Microbiol 200I, 39:1452-I463.

38. McDougald D, Srinivasan S, Rice SA, Kjelleberg S: Signal-mediated cross-talk regulates stress adaptation in Vibrio species. Microbiology 2003, 149:1923-1933.

39. Defoirdt T, Boon N, Sorgeloos P, Verstraete W, Bossier P: Alternatives to antibiotics to control bacterial infections: luminescent vibriosis in aquaculture as an example. Trends Biotechnol 2007, 25:472-479.

40. Sutcliffe JA: Improving on nature: antibiotics that target the ribosome. Curr Opin Microbiol 2005, 8:534-542.

4I. Bross MH, Soch K, Morales R, Mitchell RB: Vibrio vulnificus infection: diagnosis and treatment. Am Fam Physician 2007, 76:539-544.

42. Joelsson A, Kan B, Zhu J: Quorum sensing enhances the stress response in Vibrio cholerae. Appl Environ Microbiol 2007, 73:3742-3746.

43. Ahmed NA, Petersen FC, Scheie AA: Al-2 quorum sensing affects antibiotic susceptibility in Streptococcus anginosus. J Antimicrob Chemother 2007, 60:49-53.

44. Swartzman E, Meighen EA: Purification and characterization of a poly-(dA-dT) lux-specific DNA-binding protein from Vibrio harveyi and identification as LuxR. J Biol Chem 1993, 268:16706-16716.

45. Peeters E, Nelis HJ, Coenye T: Comparison of multiple methods for quantification of microbial biofilms grown in microtite plates. J Microbiol Methods 2008, 72:157-165.

46. Marques A, Francois JM, Dhont J, Bossier P, Sorgeloos P: Influence of yeast quality on performance of gnotobiotically grown Artemia. J Exp Mar Biol Ecol 2004, 3 1 0:247-264.

47. Bang W, Drake MA, Jaykus LA: Recovery and detection of Vibrio vulnificus during cold storage. Food Microbiol 2007, 24:664-670.

48. Freeman JA, Bassler BL: Sequence and function of LuxU: a two component phosphorelay protein that regulates quorum sensing in Vibrio harveyi. J Bacteriol 1999, 181:899-906.

49. Lenz DH, Mok KC, Lilley BN, Kulkarni RV, Wingreen NS, Bassler BL: The small RNA chaperone $\mathrm{Hfq}$ and multiple small RNAs control quorum sensing in Vibrio harveyi and Vibrio cholerae. Cell 2004, I I 8:69-82.
Publish with Bio Med Central and every scientist can read your work free of charge

"BioMed Central will be the most significant development for disseminating the results of biomedical research in our lifetime. "

Sir Paul Nurse, Cancer Research UK

Your research papers will be:

- available free of charge to the entire biomedical community

- peer reviewed and published immediately upon acceptance

- cited in PubMed and archived on PubMed Central

- yours - you keep the copyright
BioMedcentral 